\title{
Estimating the efficiency of the system of healthcare financing in achieving better health
}

\section{S. Grosskopf , S. Self \& O. Zaim}

To cite this article: S. Grosskopf , S. Self \& O. Zaim (2006) Estimating the efficiency of the system of healthcare financing in achieving better health, Applied Economics, 38:13, 1477-1488, DOI: $10.1080 / 00036840500424798$

To link to this article: http://dx.doi.org/10.1080/00036840500424798

\section{Published online: 01 Sep 2006.}

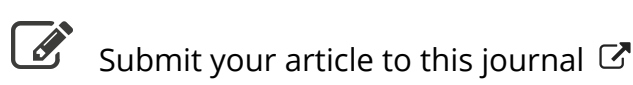

Џll Article views: 273

Q View related articles $\sqsubset$

4 Citing articles: 17 View citing articles 


\title{
Estimating the efficiency of the system of healthcare financing in achieving better health
}

\author{
S. Grosskopf ${ }^{\text {a }}$, S. Self ${ }^{b, *}$ and O. Zaim ${ }^{\mathrm{c}}$ \\ ${ }^{a}$ Department of Economics, Oregon State University, Corvallis, \\ OR 97331, USA \\ ${ }^{\mathrm{b}}$ Department of Economics, Missouri State University, Springfield, \\ MO 65897, USA \\ ${ }^{\mathrm{c}}$ Department of Economics, Bilkent University, Ankara, Turkey
}

This paper contributes to the effort to model and measure how the method of financing of health expenditure affects the efficiency with which better health can be achieved. The focus is on the health system efficiency at the country level, which provides an alternative to the work done in the WHO in this regard. The approach uses frontier techniques as in the WHO studies; however the paper appeals to the economic index number theory of quantity and productivity indexes, which have well-established axiomatic properties, and provides a means for aggregating multiple health output proxies without having to attach arbitrary weights. This allows the proposal of a specification that embeds health sector performance in a broader index of economic inputs and outputs and allows for comparisons across countries and time.

\section{Introduction}

The primary objective of this paper is to contribute to the effort to model and measure how efficiently health expenditures are translated into better health. Our focus is on health system efficiency at the country level, which is broadly similar to that used in a number of previous studies including Hadley (1982), Anell and Willis (2000), Evans et al. (2000, 2001), Tandon et al. (2000), Self and Grabowski (2003), and Thornton (2002). We depart from these earlier studies in terms of methodology. Here we follow Färe et al. (1997, 2002) and Zaim et al. (2001) and appeal to the economic index number theory of quantity and productivity indexes. These have wellestablished axiomatic properties, and provide a means for aggregating multiple health output proxies without having to attach arbitrary weights, which has plagued earlier efforts in this area. Following Zaim et al. (2001) we also propose a specification that embeds health sector performance in a broader index of economic inputs and outputs. Finally, we provide some estimates of our health sector quantity and improvement indexes to follow-up on Self and Grabowski's (2003) efforts to analyse the role of public health expenditures on health sector performance at various levels of development.

According to the Disability Adjusted Life Expectancy (DALE) rankings of countries in the World Health Report (2000), wealthier countries with a large public sector involvement in health care have higher DALE rankings. Although this suggests that reliance on health expenditures funded through the public sector are responsible for the longer and

*Corresponding author. E-mail: sself@csbsju.edu 
healthier lives, Self and Grabowski (2003) find that public health expenditures face diminishing returns in developed countries, when DALE is used to measure health. It is in the LDCs that public health expenditures have a significant positive impact on DALE, yet in these countries public health expenditures contributed far less towards funding of health care than the developed countries. The present paper draws its motivation from the results of Self and Grabowski (2003) but extends the analysis by introducing health system efficiency instead of health system output as measured by DALE. Similar results in relation to health expenditure are reflected in Berger and Messer (2002), Thornton (2002) and Fayissa and Gutema (2005). Fayissa and Gutema estimate a health production function for sub-Saharan Africa and find that health policy, which does not include socioeconomic and environmental aspects, does little to improve the health status of the region. In Berger and Messer, who study the effects of public financing of health expenditures, among other factors, on health outcomes in 20 OECD countries for 1960 to 1992, increases in health care expenditures are found to be associated with increased mortality rates. Thornton finds that additional medical care utilization is mostly ineffective in lowering mortality and increasing life expectancy for the population of the USA.

We use recently developed frontier methods that allow us to calculate our health sector quantity indexes and efficiency without requiring data on prices or shares. These measures can be used to construct Malmquist quantity and productivity indexes, whose component distance functions can be estimated using linear programming models equivalent to the nonparametric methods used in data envelopment analysis (DEA). Using this approach, a 'best practice' frontier is constructed and each observation is compared to that frontier as part of the optimization process.

The rest of the paper is as follows. Section II provides a description of the methodology used in our analysis, Section III explains the specification of inputs and outputs used in our different model efforts, Section IV discusses the results and Section V concludes.

\section{Methodology}

Our methodology is motivated as an alternative to the approach taken by Evans et al. in their working paper 'The comparative Efficiency of National Health Systems in Producing Health'. ${ }^{1}$ The authors' goal is to compare health system performance across countries and across time. ${ }^{2}$ The authors estimate a frontier production function using panel data from 1993 to 1997 for 191 WHO member countries. Health output is measured by Disability Adjusted Life Expectancies (DALE) and inputs by health expenditures per capita. They also control for average years of schooling.

This section closely follows Zaim et al. (2001) and Färe et al. (2002). Beginning with our notation, suppose we observe a sample of $k=1, \ldots, K$ countries each of which use inputs $x^{k}=\left(x_{1 k}, \ldots, x_{N k}\right)$, to produce a vector of outputs $y^{k}=\left(y_{1 k}, \ldots, y_{M k}\right)$, which may be a vector of health indicators, for example. If we assume that knowledge is at least potentially transferable across countries, we can posit a best practice 'meta'-technology. Since we are interested in among other things output quantity indexes, the meta technology we are interested in is the output or production possibility set, i.e.

$$
P(x)=\{y: x \text { can produce } y\}, \quad x \in R_{+}^{N}
$$

consisting of all output vectors that can be produced by the given input vector or available resources. Following the axiomatic approach, we impose minimal regularity conditions on the technology as in Zaim et al. (2001). Since we are interested in constructing (scalar) indexes of health output and performance, we seek a function representation of the technology above that preserves its properties. As proposed originally by Malmquist (1953) distance functions are useful in building quantity indexes with desirable properties. Here we use the output distance function both to represent technology and gauge the performance of individual observations relative to the best practice frontier of that technology. We define the output distance function for country $k$ as

$$
D_{o}\left(x^{k}, y^{k}\right)=\inf \left\{\theta^{k}: y^{k} / \theta^{k} \in P(x)\right\} .
$$

This function expands the output vector (i.e. $y^{k}$ ), so that the expanded output vector is projected onto the best practice frontier of $P(x)$. This function serves as representation of technology, aggregator function and performance measure. It is homogeneous of degree +1 in outputs and it inherits its properties from the technology $P(x)$. Since we do not directly observe the common frontier technology, we construct it from the observed inputs and outputs of the countries in our sample. Here we employ an

\footnotetext{
${ }^{1}$ GPE disc paper series 29, WHO 2000.

${ }^{2}$ In a companion working paper by the same authors they take on the broader issue of comparing health across countries.
} 
Activity Analysis or Data Envelopment Analysis (DEA) approach, which satisfies the properties of the underlying technology; see, for example, Färe and Grosskopf (1996).

The DEA or piecewise linear output set may be written for country $k^{\prime}$ as

$$
\begin{aligned}
P\left(x_{k^{\prime}}\right)= & \left\{y \in R_{+}^{M}:\right. \\
& \sum_{k=1}^{K} z_{k} y_{k, m} \geq y_{m}, \quad m=1, \ldots, M \\
& \sum_{k=1}^{K} z_{k} x_{k, n} \leq x_{n}, \quad n=1, \ldots, N \\
& \left.z_{k} \geq 0, \quad k=1, \ldots, K\right\}
\end{aligned}
$$

where the $Z_{k}$ are the intensity variables, which serve to form the technology from convex combinations of the data.

The distance function is a performance measure in its own right (it is the reciprocal of Farrell technical efficiency) and serves as the basis of our health quantity indexes and eventually our productivity indexes. In constructing the quantity index, we are focusing on deriving a scalar index of outputs that holds the other variables constant at a given reference level. Let $x^{o}$ and $y^{\circ}$ be the vectors of inputs and outputs for a reference observation and let $y^{k}$ be observations of the vector of outputs for the observation under evaluation. Following the general idea proposed by Malmquist (in the consumer context), we define our quantity index of health output as

$$
Q\left(x^{o}, y^{o}, y^{k}\right)=D\left(x^{o}, y^{k}\right) / D\left(x^{o}, y^{o}\right)
$$

This index indicates whether the quantity of health $y^{k}$ is larger or smaller than that of the reference, $y^{o}$, holding inputs constant at the reference levels $o$. For a discussion of the theoretical underpinnings of various index numbers, see Diewert (1979). Clearly this could allow for comparisons of a single country over time, or to comparisons across countries. This quantity index, which is essentially a Malmquist quantity index, satisfies a number of desirable properties due to Fisher (1922). These include homogeneity, time-reversal, transitivity and dimensionality. See Fisher (1922) or Zaim et al. (2001).

Following Zaim et al. (2001) we also extend this general model to what they refer to as an improvement index. This is essentially a modified Malmquist productivity index, which measures the success of a particular country in expanding its outputs from year to year measured with respect to a common (world) benchmark technology constructed for each period.

In order to estimate the distance functions that form the index we take advantage of the fact that distance functions are reciprocals of Farrell technical efficiency measures and compute them as solutions to simple linear programming or Data Envelopment Analysis (DEA) problems following the name coined by Charnes et al. (1978). For each of the countries in our data set $k^{\prime}=1, \ldots, K$ we may estimate the following distance function

$$
\left(D\left(x^{o}, y^{k^{\prime}}\right)\right)^{-1}=\max \theta
$$

s.t.

$$
\begin{aligned}
\sum_{k=1}^{K} z_{k} y_{k, m} \geq \theta y_{k^{\prime}, m}, \quad m=1, \ldots, M \\
\sum_{k=1}^{K} z_{k} x_{k, n}=x_{o^{\prime}, n}, \quad n=1, \ldots, N \\
Z_{k} \geq 0, \quad k=1, \ldots, K
\end{aligned}
$$

which is the numerator for $Q\left(x^{o}, y^{o}, y^{k}\right)$. The denominator is computed by replacing $y_{k^{\prime}, m}$ on the righthand-side of the output constraints with $y_{o, m}$, the observed output vector for the reference country $o$. Again, the $z_{k}$ variables are intensity variables which serve to construct the best practice frontier from the observed data, i.e. the inequality constraints are modified from $P(x)$ above. The solution value estimates the scaling factor on outputs required for each observation to attain best practice. We also estimate a version in which we scale on a sub-vector of outputs, namely the health status outputs.

We also estimate a Malmquist productivity index which is closely related to the index above, but explicitly compares observations to technologies in different time periods. Following the original definition proposed by Caves et al. (1982) this index may be written as

$$
M^{t}=D^{t}\left(x^{t+1}, y^{t+1}\right) / D^{t}\left(x^{t}, y^{t}\right) .
$$

The index compares data in adjacent periods, $t$ and $t+1$. We follow Färe et al. (1994) and use a geometric mean form of this index.

\section{Specification of Inputs and Outputs}

We estimate a health sector quantity index and a health productivity or improvement index as well as reporting the basic efficiency measure results. Our data for the health sector quantity index are 
from the World Bank's World Development Indicators (2002). We use data from the World Bank Social Indicators database and Penn World Tables for our productivity index. For our health sector quantity indexes our sample consists of 143 countries in the year 1997. For the 1997 sample, we have 66 middle-income countries (including upper and lower middle income), 48 low-income countries or LDCs and 28 developed countries based on the World Bank's country classifications.

We begin with our health quantity index which is closely related to the achievement index in Zaim et al. (2001). That index was designed as an alternative to the 'aggregate deprivation index' often used to measure well-being of individuals in different countries. As proxies for social goods Zaim et al. use the infant survival rate, life expectancy at birth, primary school enrollment rate, and secondary school enrollment rate. Real GDP was included as a proxy for the quantity of private goods available. Their resource constraints included two aggregate inputs, capital stock and labour. Their index was not intended to be a health index, although looking at the impact of socio-economic conditions on health is not new to the health literature (Zurayk et al., 1997; Evans et al., 2001; Meara, 2001; Nordhaus, 2002; Thornton, 2002; Self and Grabowski, 2003). The most frequently used socioeconomic variables are measures of schooling and income. The importance of schooling on health is well established in the literature (Grossman, 1975; Caldwell, 1979; Rosen and Taubman, 1982; Caldwell and Caldwell, 1985; Elo and Preston, 1996; Filmer and Pritchett, 1999). The relationship between income and health has also been widely studied (Preston, 1975; Fuchs, 1994; Pritchett and Summers, 1996) and argued about (Evans et al., 2001).

In this paper, we draw from the existing health literature as well as from Zaim et al. (2001). We begin with a simple health sector model, and then move to models which include other socioeconomic factors. In the first model, we focus on the health sector and measure health sector output as a vector of variables including life expectancy at birth and the reciprocal of the under-five mortality rate, which were the most frequently reported health outcomes proxies available in the 1997 data set. The inputs to the health sector are private and public health expenditures as a percentage of per capita GDP. ${ }^{3}$ In the next set of enhanced models, which are closer to the achievement index of Zaim et al., health sector outputs are measured by the life expectancy (models $2 \mathrm{a}$ and $2 \mathrm{~b}$ ) at birth and the reciprocal of the under-five mortality rate as before (2a), but we augment outputs to include per capita GDP. The health sector inputs are again the share of GDP spent on private and public health expenditure, but we also introduce broader economic inputs namely gross capital formation per capita and the per capita labour force. The last set of models augments these to include a measure of human capital as input, i.e. the enrollment rate in primary education.

For our improvement or health productivity indexes, data availability dictated slightly different specifications. Here again we have life expectancy and infant survival as health output proxies, and real GDP per worker as our broader economic output proxy. Health expenditure data was not available consistently over the years we included (1977, 1980, 1982, 1987 and 1990). Our input vector included the labour capital ratio as well as primary and secondary education enrollment rates. Our sample size is smaller for the improvement index: 27 developed countries, 19 middle income countries and 9 LDCs.

These model specifications are largely dictated by data availability; obviously alternative specifications with more detailed data would be welcome.

\section{Results}

We begin with our basic technical efficiency results, then move on to (static) health quantity indexes and finally turn to the improvement indexes which track performance over time. Our static health sector quantity indexes are multilateral indexes, i.e. we can compare our countries since they have all been compared to a common base, namely the hypothetical country formed from the mean values of the variables. Thus values greater than one indicate that the country in question has a higher quantity index of health than our hypothetical average country. By definition, our 'average' country will have index values identically equal to one.

For our basic efficiency measures and static quantity indexes we specify a number of different models; see the table in the previous section for a summary of the models we present here. Table 3a summarizes the results for the basic technical efficiency measure in which each country is compared to the best practice frontier using the various model specifications found in Table 1. The values in this table may be interpreted as the ratio of maximum potential output(s) to observed output(s), given

\footnotetext{
${ }^{3}$ Since our output measures are in 'rate' form, we use health expenditure shares rather than totals to be consistent with our output measures.
} 
Table 1. Model specifications - health quantity indexes

\begin{tabular}{|c|c|c|c|c|c|}
\hline & Model 1 & Model 2a & Model 2b & Model 3a & Model 3b \\
\hline \multicolumn{6}{|l|}{ Outputs } \\
\hline Life exp. & $\mathrm{x}$ & $X$ & $\mathrm{x}$ & $X$ & $\mathrm{x}$ \\
\hline$(\text { Infant mortality })^{-1}$ & $\mathrm{x}$ & $\mathrm{X}$ & & & $\mathrm{x}$ \\
\hline GDP/pop. & & $\mathrm{X}$ & $\mathrm{x}$ & $\mathrm{X}$ & $\mathrm{x}$ \\
\hline \multicolumn{6}{|l|}{ Inputs } \\
\hline$\%$ Public health exp. & $\mathrm{x}$ & $\mathrm{X}$ & $\mathrm{x}$ & $\mathrm{X}$ & $\mathrm{x}$ \\
\hline$\%$ Pvte health exp. & $\mathrm{x}$ & $X$ & $\mathrm{x}$ & $\mathrm{X}$ & $\mathrm{x}$ \\
\hline Labour/pop. & & $X$ & $\mathrm{x}$ & $X$ & $\mathrm{x}$ \\
\hline Cap./pop. & & $X$ & $\mathrm{x}$ & $\mathrm{X}$ & $\mathrm{x}$ \\
\hline Primary enroll. rate & & & & $\mathrm{X}$ & $\mathrm{x}$ \\
\hline
\end{tabular}

observed inputs and technology, i.e. values greater than unity give the factor by which observed output could be enhanced if it were on the best practice frontier. Values equal to one signal best practice performance. In the table we report the mean values for the sample as a whole as well as by development level. Model 1 is our simplest specification (the fewest inputs and outputs) and has the highest average efficiency scores in each category, i.e. this model has the highest average inefficiency. In every case we see that inefficiency increases as we move from developed, to middle to less developed countries. Health performance is most efficient in the developed countries according to our simple efficiency scores.

Next we turn to our quantity indexes. In order to get some sense of the distribution of our results under the various model specifications we start with plots of our results. Since we are interested in the role of health finance, we plot our indexes against the ratio of public to private health expenditure.

In Fig. 1 we have plotted the health index values (here values greater than one indicates above-average health performance) against the ratio of public health expenditure to private health expenditure (as a share of GDP). Here, health output is measured by the inverse of infant fertility and life expectancy and the input is the share of GDP which is used to fund public and private health expenditure. The average ratio of public to private health expenditure is 2.12 , that is, on average public health spending accounts for twice the share of private spending on health. There is a positive correlation between the health expenditure ratio and the health index. The correlation value stands at 0.5 . Note there are several countries with health index values of 1 or above which indicates average or above average health performance.

Next, in model 2, we broaden our definition of health even further, in the spirit of Zaim et al. Here, the health output vector includes life expectancy and

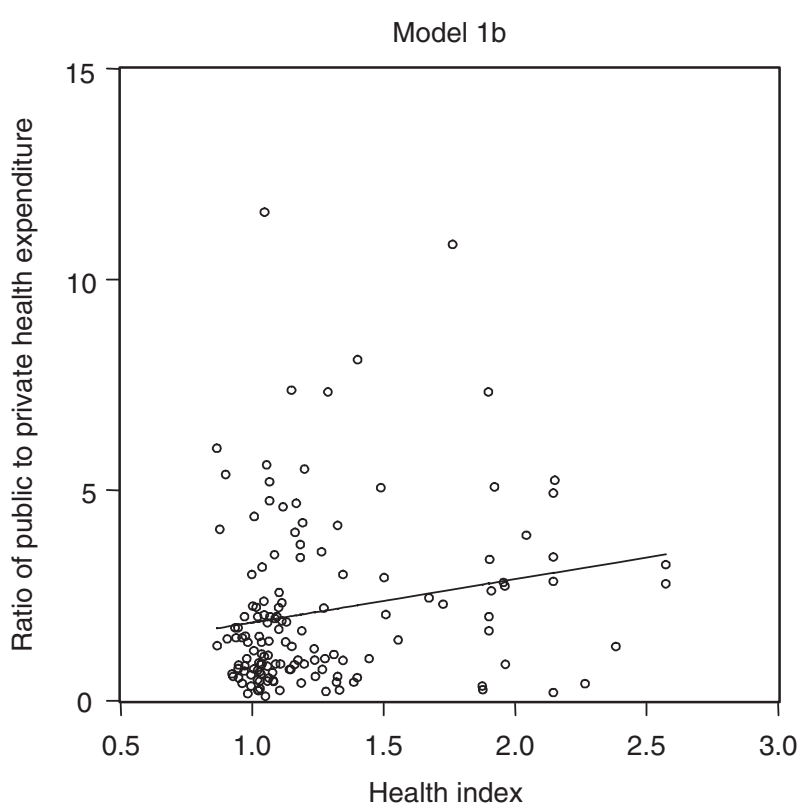

Fig. 1. Estimating the efficiency of the system of healthcare financing in achieving better health: model $1 \mathrm{~b}$

the reciprocal of the infant mortality rate, and is augmented to include per capita income. This broader index includes our original health expenditure variables as inputs but also includes measures of labour and capital. The graph in Fig. 2 details the correlation between the ratio of health expenditures and the new health index.

Here too, we see a positive correlation as the model before. The correlation between the two variables stands at 0.54 . In the next model (Fig. 3), we exclude the mortality measure (inverse of infant mortality) from the health definition and leave all other factors unchanged. The relation between the health expenditure ratio and the health index is presented below. Excluding the mortality measure from the health definition does not seem to affect the correlation 


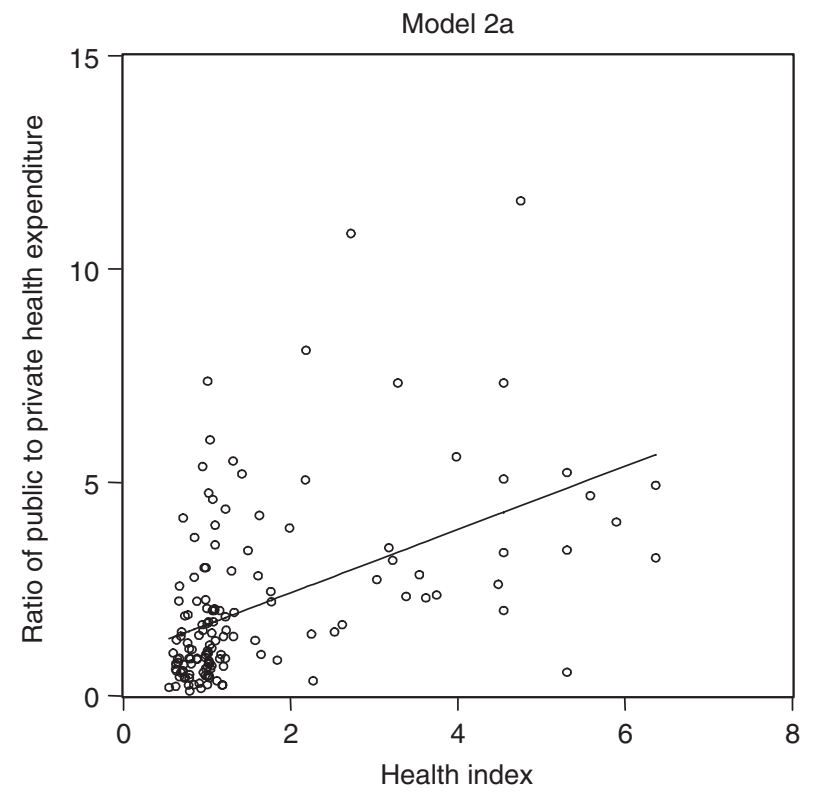

Fig. 2. Estimating the efficiency of the system of healthcare financing in achieving better health: model $2 \mathrm{a}$

between the health expenditure ratios and the health index very significantly which now stands at 0.46 .

Next we construct two more versions of the health index by adding a measure of education (primary education enrollment rates) as an input into the health production function. When we do this, our sample size for all countries taken together shrinks to 99 compared to 143 earlier. In the first version, health output is measured by life expectancy and per capita GDP with the associated health expenditure variables, primary education enrollment rates, and our capital and labor variables. In the second version, we add to the health output and per capital GDP the inverse of infant mortality as well. All inputs and resource constraints are identical.

The chart (Fig. 4) plots the health index associated with model 3 a against the ratio of public to private health expenditure.

There is a positive correlation of 0.29 between the health expenditure ratio and the health index as per model 3a. However, here we see a relatively larger cluster of countries with health index value less than 1 which represents the average in the sample. These countries typically appear to have very small shares of publicly funded health care. When we include the reciprocal of infant mortality as an output indicator and carry out a similar exercise, we find similar results.

Again, the graph (Fig. 5) shows a positive correlation between the ratio and the health index with a value of 0.36 . If we organize our results by the World Bank wealth/income categories we see that the

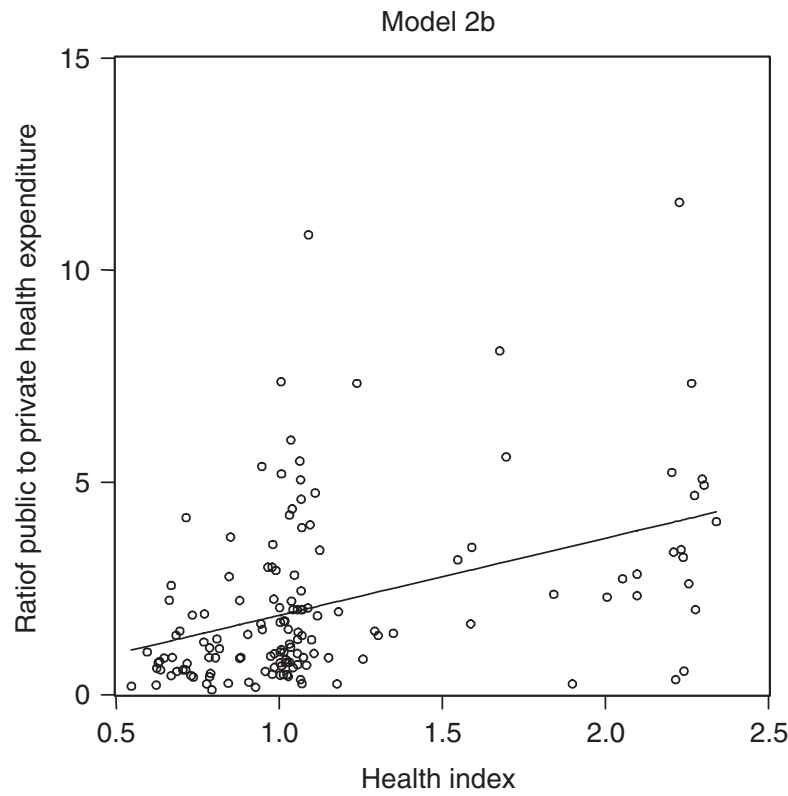

Fig. 3. Estimating the efficiency of the system of healthcare financing in achieving better health: model $2 b$

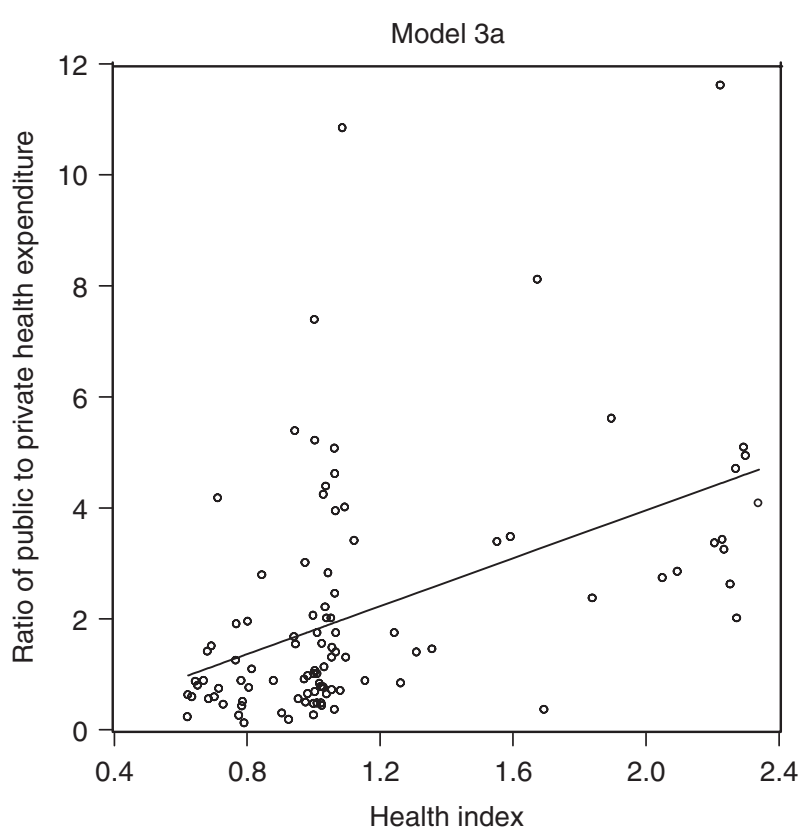

Fig. 4. Estimating the efficiency of the system of healthcare financing in achieving better health: model 3a

different models yield different orderings of results by development category; see Table $3 b$.

For the simple health sector model with life expectancy and the infant survival rate as output proxies, the average quantity indexes are highest for developed countries and lowest for middle income countries. When we augment the model to include per 
capita GDP as an output and add labour, capital and education variables to the input vector, we see that developed countries have the highest indexes and less developed countries have the lowest.

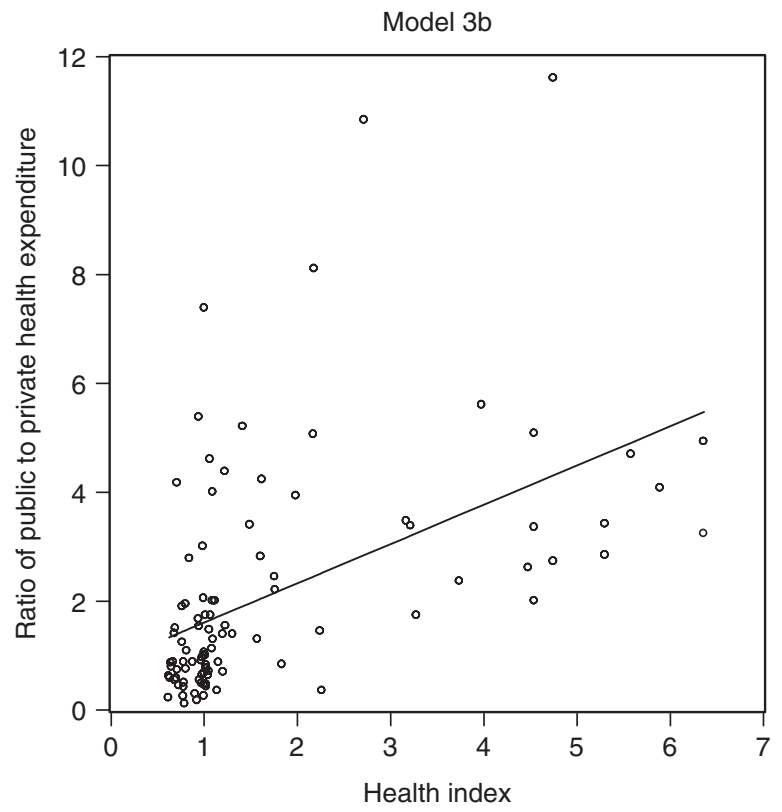

Fig. 5. Estimating the efficiency of the system of healthcare financing in achieving better health: model $3 \mathrm{~b}$
The variation in the mean values observed in Table $3 \mathrm{~b}$ is generally small therefore we conducted a test of equality between the series by conducting an analysis of variance (ANOVA) test. The null hypothesis of the series having equal means is rejected. Thus we can say the health indexes across the different country categories are significantly different. However, we would really like to know where the source of this difference lies.

Again we would like to know whether the source of financing of the health care sector can help to explain the variation in our indexes. The last column of Table $3 b$ displays the mean values of the ratio of public to private health expenditures for the countries in our sample by income group. Clearly, the relative role of the public sector is much greater in developed and middle income countries than in less-developed countries. Thus we again see some evidence of the correlation between the financing of the health care system and our indexes of health which we observed in our plots. When we compute correlation indexes between the type of funding and the health index, we find as expected from our plots that these correlations are very weak. When we break this out by income group we find that for the middle income countries there is a stronger positive relationship, although this varies by specification.

Table 2. Model specifications - improvement indexes

\begin{tabular}{llll}
\hline $\begin{array}{l}\text { Outputs } \\
\text { Inputs }\end{array}$ & Life exp. & (Infant mortality) $^{-1}$ & GDP/labour \\
& Lab/cap & Primary enroll. rate & Secondary enroll. rate \\
\hline
\end{tabular}

Table 3a. Means - technical efficiency measures

\begin{tabular}{llllll}
\hline Sample & Model 1 & Model 2a & Model 2b & Model 3a & Model 3b \\
\hline Total & 1.2181 & 1.1273 & 1.1282 & 1.1144 & 1.1127 \\
Developed & 1.0290 & 1.0086 & 1.0100 & 1.0072 & 1.0048 \\
Middle & 1.1386 & 1.0917 & 1.0930 & 1.0830 & 1.0815 \\
LDCs & 1.4417 & 1.2479 & 1.2479 & 1.2223 & 1.2206 \\
\hline
\end{tabular}

Table 3b. Means - health quality indexes

\begin{tabular}{lllllll}
\hline Sample & Model 1 & Model 2a & Model 2b & Model 3a & Model 3b & $\begin{array}{l}\text { Pub/pvte } \\
\text { health exp. }\end{array}$ \\
\hline Total & 1.2648 & 1.6083 & 1.1417 & 1.1515 & 1.7162 & 1.6068 \\
Developed & 1.9178 & 3.767 & 1.9217 & 1.9513 & 4.1139 & 3.5271 \\
Middle & 1.1051 & 1.1996 & 1.0205 & 1.0122 & 1.23 & 1.6918 \\
LDCs & 1.1253 & 0.803 & 0.8058 & 0.803 & 0.803 & 0.6828 \\
\hline
\end{tabular}


Next we move on to a more dynamic analysis by looking at our results for the improvement or productivity index which allows us to track performance over time. Here our specification is somewhat different due to the different data sources. The health output proxies are again life expectancy and infant survival rates with real GDP per worker as our broader economic proxy. Data on health expenditures was not consistently available over our time period; the inputs included are the labor capital ratio, and primary and secondary school enrollment rates.

Figures 6-14 show plots of our results. The first three figures plot the changes in the improvement index for the periods 1977 to 1980,1980 to 1982, 1982 to 1987 and 1987 to 1990 for our three development categories. Each bar represents the range of the values of the index for each of these time periods; the cross bar gives the mean value for that period. For LDCs we see that there is some upward movement over time, although values at the mean hover below one until the last time frame, when it increases to unity.

For the developed countries, the dispersion is smaller, and the mean value starts slightly above one, indicating an initial improvement, but then settles in at about unity, i.e. no change. The middle income countries also show no strong pattern over our time period, again hovering around unity with a slight uptick in the mean and reduction in variance in the last time period.

Next we turn to similar plots for cumulated improvement indexes. Here we cumulate the changes; i.e. the first vertical bar gives the improvement between 1977 and 1980, the next bar gives the improvement between 1977 and 1982, the next between 1977 and 1987 and the final bar gives the total cumulated change in the improvement index over the 1977 to 1990 periods. Again, we find very little variation for the developed countries; however,

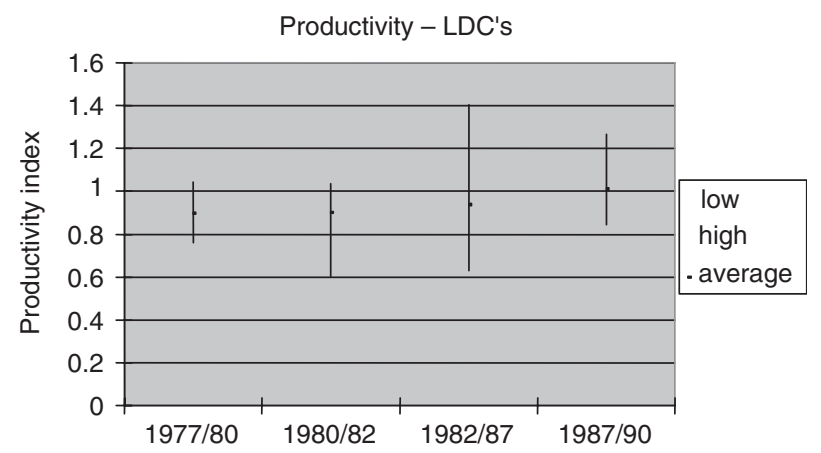

Fig. 6. Productivity - less-developed countries

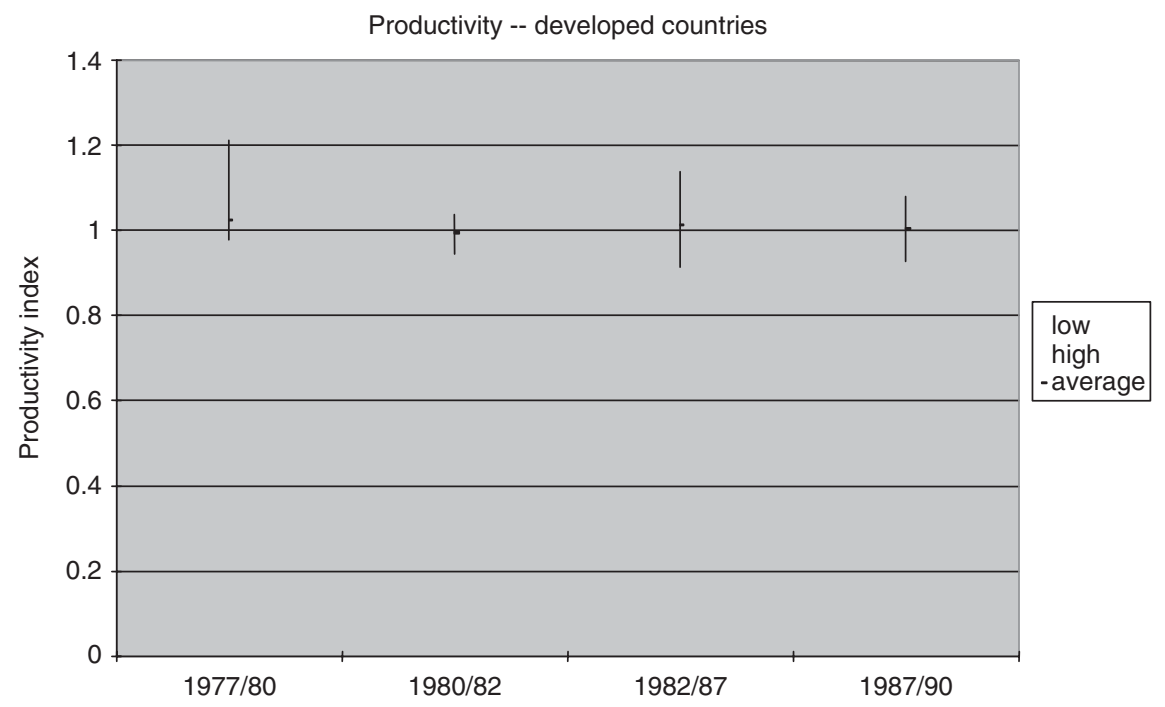

Fig. 7. Productivity - developed countries 


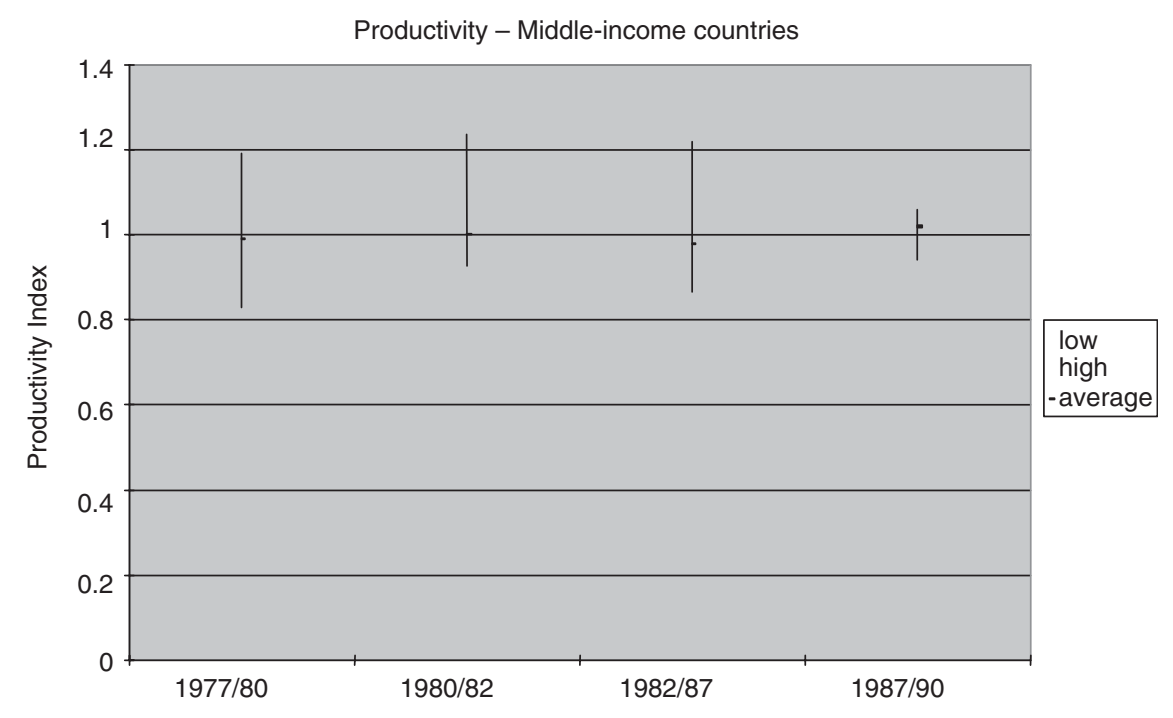

Fig. 8. Productivity - middle-income countries

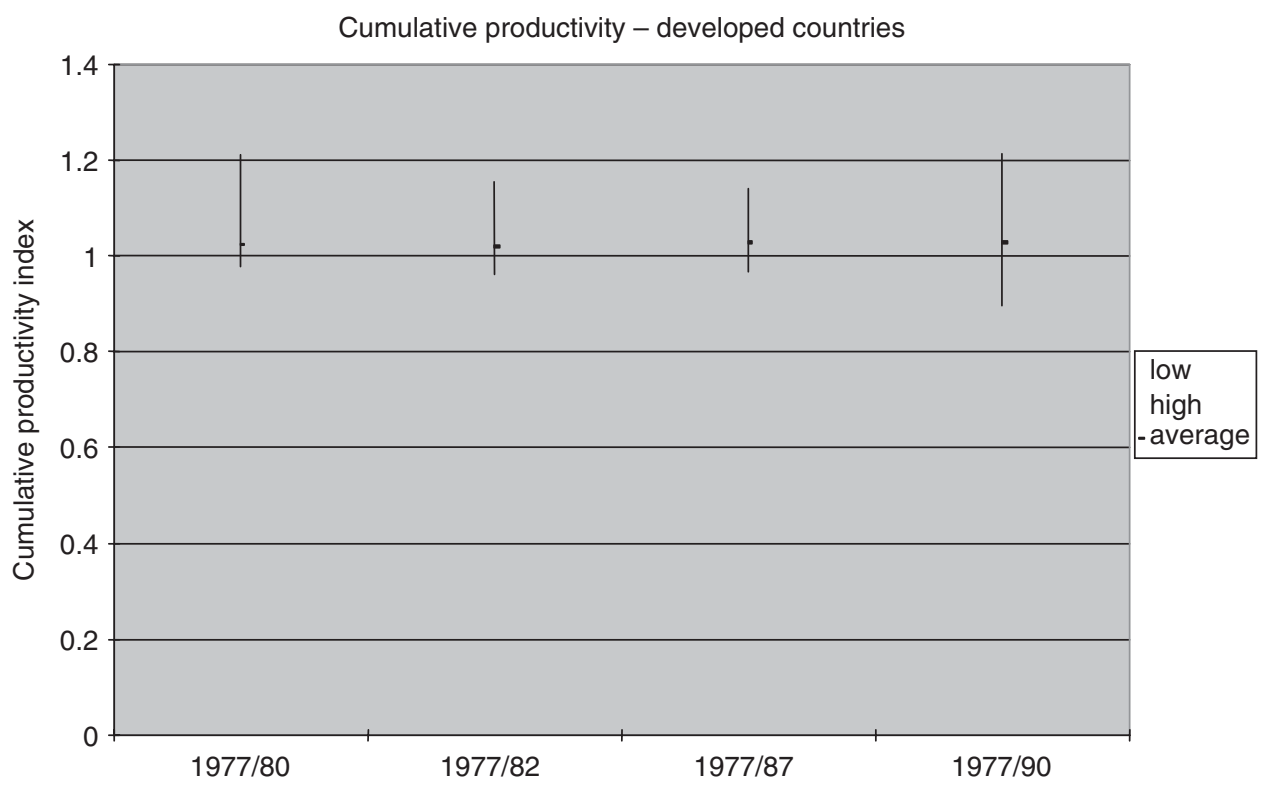

Fig. 9. Cumulative productivity - developed countries

the mean cumulated improvement is consistently above unity indicating improvements on average.

For the middle income countries we see greater dispersion and cumulated means that hover slightly below unity. The LDCs exhibit increasing dispersion over time and means persistently below unity indicating declining performance over the time period on average.

Table 4 summarizes our cumulated improvement index results by development status and years.

Again we tested for equality (ANOVA) across the series and reject the null of equality. We report the average public health expenditure as a percentage of GDP in 1960 in the last row of Table 4, which suggests that public health expenditure share may be related to stage of development.

Finally, in Figs 12-14 we plot the cumulated productivity indexes against the 1960 public health expenditure; here we see that the relationship varies distinctly by level of development.

The correlation values for the LDCs, the middleincome countries, and the developed countries are $-0.07,0.2$, and -0.35 respectively. The LDCs show a very weak negative relationship between 


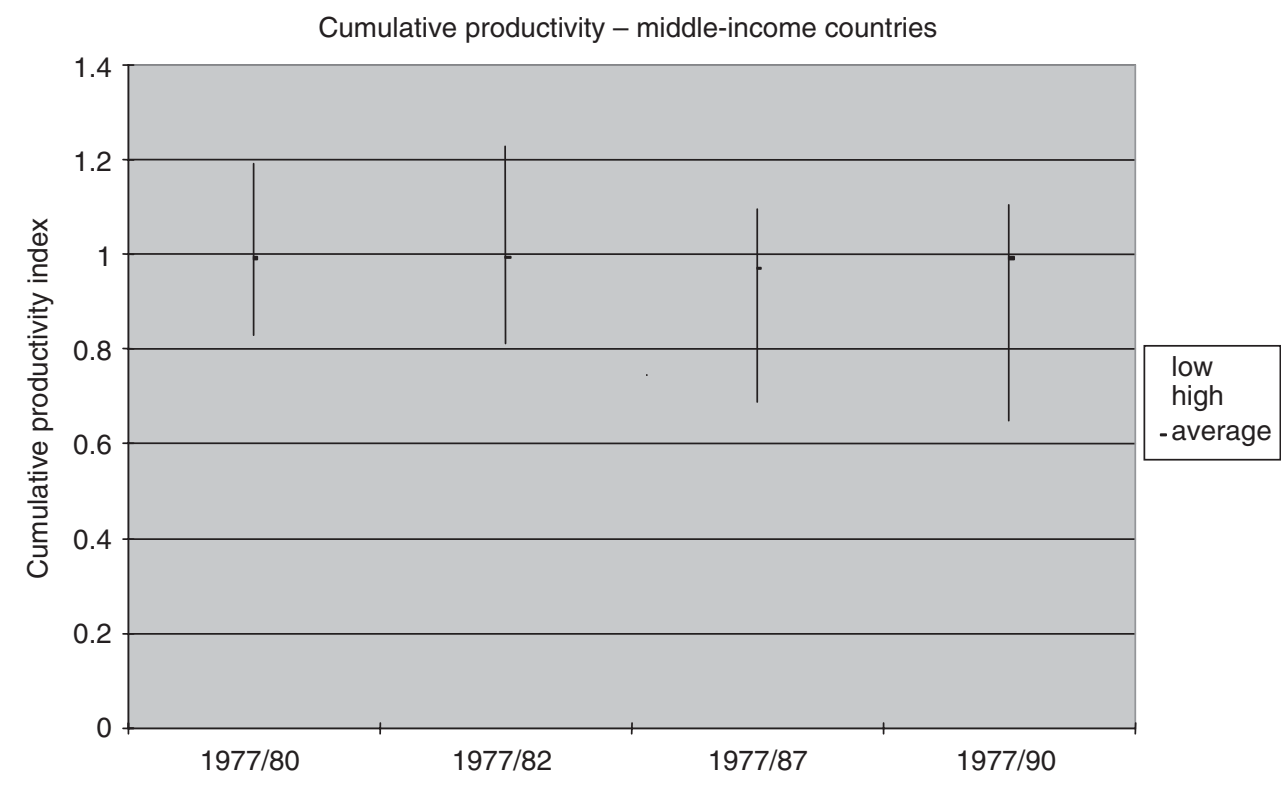

Fig. 10. Cumulative productivity - middle-income countries

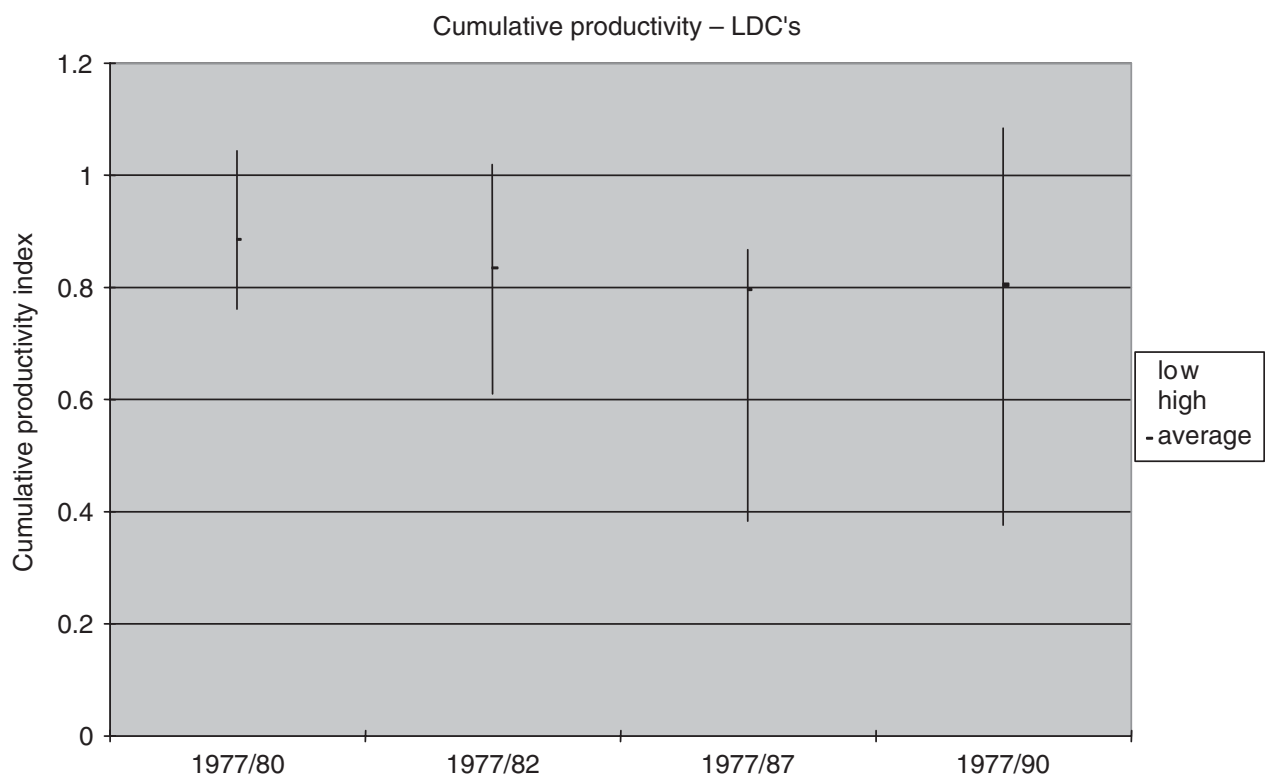

Fig. 11. Cumulative productivity - less-developed countries

public health expenditure in 1960 and the cumulative health index over time. The developed countries exhibit a much stronger negative relationship, i.e. countries with relatively low public sector shares in 1960 had higher cumulated improvement indexes than developed countries with relatively higher shares. The only positive relationship shows up for the middle income countries. This corroborates the basic results of Self and Grabowski (2003).

\section{Conclusions}

To sum up, in this paper we add to the body of literature which attempts to model and measure how health sector inputs are translated into health outcomes. In contrast to most of the earlier studies, we appeal to the economic axiomatic index number theory and efficiency literature to define both our multilateral health sector quantity indexes and our panel-based improvement index. This allows us to 


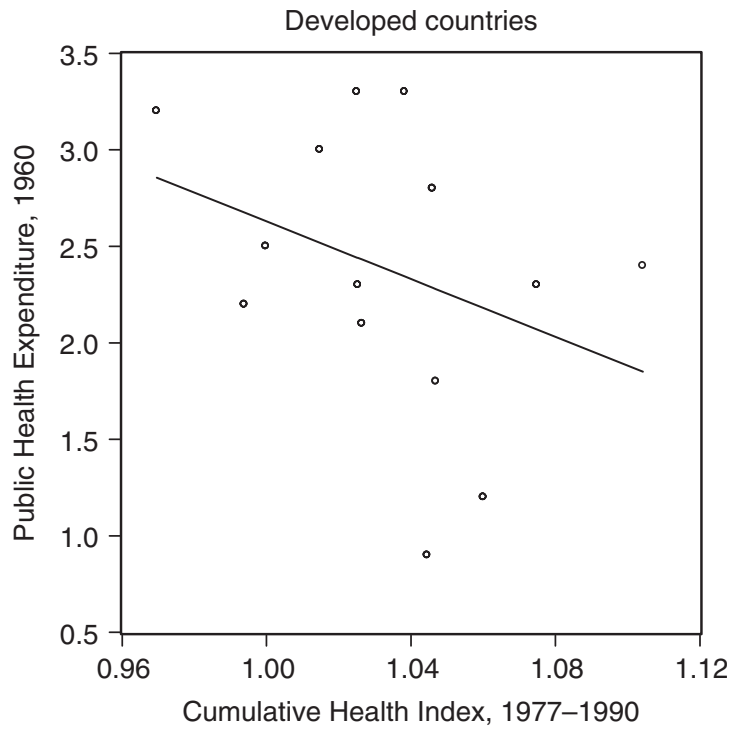

Fig. 12. Cumulative health index - developed countries

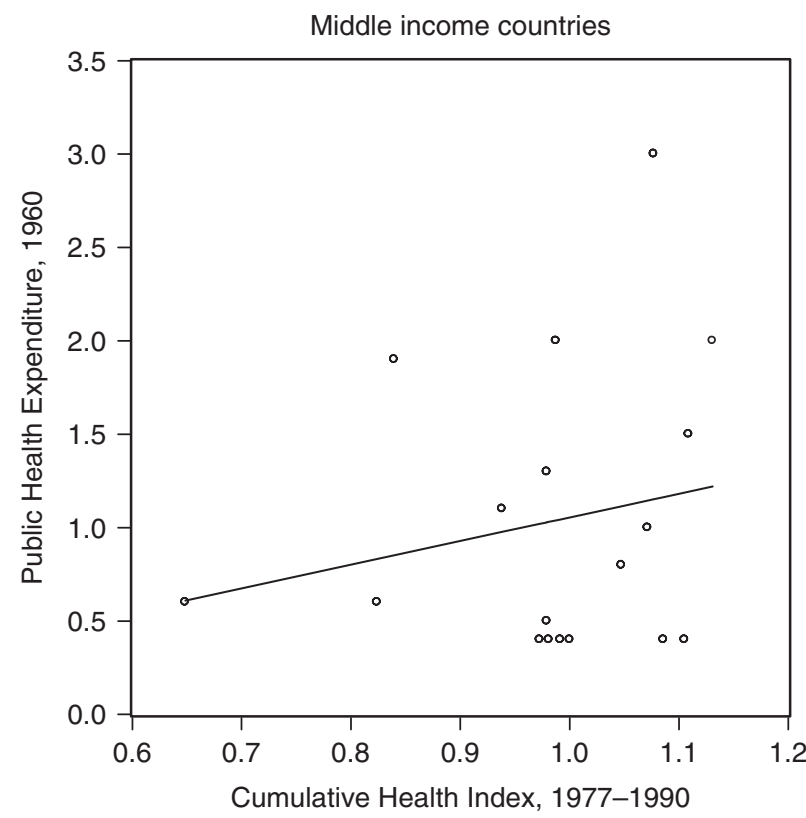

Fig. 13. Cumulative health index - middle-income countries

aggregate across health outcomes without introducing arbitrary weights and allows us to compare health sector performance across countries and over time. We employ frontier methods to estimate these indexes. It is seen from our sample that the relative role of the public sector in health care financing is much greater in developed and middle income countries than in less-developed countries. Based on a cross-section sample of countries we find that developed countries typically have above average performance based on several specifications of

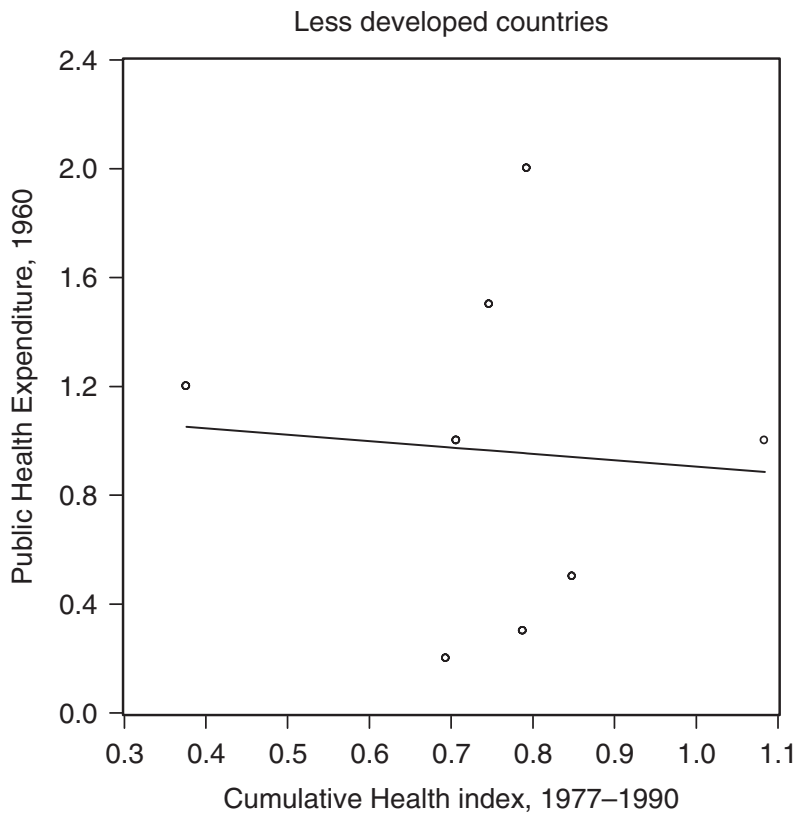

Fig. 14. Cumulative health index - less-developed countries

Table 4. Means - improvement indexes, average annual change

\begin{tabular}{lllll}
\hline Year & Total & Developed & Middle & LDCs \\
\hline $1977 / 80$ & 0.99135 & 1.02425 & 0.99323 & 0.8946 \\
$1980 / 82$ & 0.97749 & 0.99953 & 0.99393 & 0.8794 \\
$1982 / 87$ & 0.96565 & 0.99441 & 0.96496 & 0.8957 \\
$1987 / 90$ & 1.00635 & 0.99856 & 1.02459 & 0.9817 \\
\% Public & & 2.3786 & 1.0389 & 0.9625 \\
\hline
\end{tabular}

the model. We also find weak positive correlations between performance and the relative reliance on public funding of the healthcare sector. That is, while the developed countries show signs of having better health, as measured by various different specifications, it does not necessarily imply that this is a result of reliance on a larger share of publicly funded healthcare.

We also estimate an improvement index based on frontier productivity measures for the period 1977 to 1990 , which allows us to compare performance across countries and over time. As with our static results, we find that improvement varies by level of development; and again there is no simple relationship between reliance on public funding of health. This too varies by level of development with only middle-income countries showing a positive relationship between public funding and improvements in overall health or quality of life for our sample period. The relation is negative for LDCs as well as developed countries, although the negative 
correlation is much stronger for the developed countries. This implies that for our sample of developed countries there is evidence of convergence between the initial shares of publicly funded health care and improvement in overall health.

\section{References}

Anell, A. and Willis, M. (2000) International comparison of health care systems using resource profiles', Bulletin of the World Health Organization, 78, 770-78.

Berger, M. C. and Messer, J. (2002) Public financing of health expenditures, insurance, and health outcomes, Applied Economics, 34, 2105-113.

Caldwell, J. C. (1979) Education as a factor of mortality decline: an examination of Nigerian data, Population Studies, 33, 395-413.

Caldwell, J. C. and Caldwell, P. (1985) Education and literacy as a factor of health, in Good Health at Low Cost (Eds) S. B. Halstead, J. L. Walsh and K. S. Warren, Rockefeller Foundation, New York, pp. 181-85.

Caves, D., Christensen, L. and Diewert, W. E. (1982) The economic theory of index numbers and the measurement of input, output and productivity, Econometrica, 50, 1393-414.

Charnes, A., Cooper, W. W. and Rhodes, E. (1978) Measuring the efficiency of decision making units, European Journal of Operational Research, 2, 429-44.

Diewert, W. E. (1979) The economic theory of index numbers: a survey, Discussion Paper No. 79-09, Department of Economics, University of British Columbia.

Elo, I. and Preston, S. H. (1996) Educational differentials in mortality: United States, 1979-85, Social Science and Medicine, 42, 47-57.

Evans, D. B., Tandon, A., Murray, C. J. L. and Lauer, J. (2000) The comparative efficiency of national health systems in producing health: an analysis of 191 countries, GPE Discussion Paper 29, World Health Organization.

Evans, D. B., Tandon, A., Murray, C. J. L. and Lauer, J. (2001) Comparative efficiency of national health systems: cross national econometric analysis, British Medical Journal, 323, 307-10.

Färe, R. and Grosskopf, S. (1996) Intertemporal Production Frontiers: With Dynamic DEA, Kluwer Academic Publishers, Boston, MA.

Färe, R., Grosskopf, S. and Lovell, C. A. K. (1994) Production Frontiers, Cambridge University Press, Cambridge.

Färe, R., Grosskopf, S., Lindgren, B. and Poullier, J. P. (1997) Productivity growth in health care delivery: a comparison of OECD countries, Medical Care, 35, 354-66.

Färe, R., Grosskopf, S., Odegaard, F. and Roos, P. (2002) Measuring efficiency and productivity changes from investments in employees' health, Paper presented at the 7th North American Productivity Workshop, Union College.

Fayissa, B. and Gutema, P. (2005) Estimating a health production function for sub-Saharan Africa (SSA), Applied Economics, 37, 155-64.

Filmer, D. and Pritchett, L. (1999) The effect of household wealth on educational attainment: evidence from 35 countries, Population and Development Review, 25, 85-120.

Fisher, I. (1922) The Making of Index Numbers, Houghton-Mifflin, Boston, MA.

Fuchs, V. R. (1994) The Future of Health Policy, Harvard University Press, Cambridge, MA.

Grossman, M. (1975) The correlation between health and schooling, in Household Production and Consumption (Ed.) N. E. Terleckyj, Columbia University Press, New York, pp. 147-211.

Hadley, J. (1982) More medical care, better health? Urban Institute, Washington, DC.

Malmquist, S. (1953) Index numbers and indifference surfaces, Trabajos de Estadistica, 4, 209-42.

Meara, E. (2001) Why is health related to socioeconomic status? Working paper w8231, National Bureau of Economic Research.

Nordhaus, W. D. (2002) The health of nations: the contribution of improved health to living standards, Working paper w8818, National Bureau of Economic Research.

Preston, S. H. (1975) The changing relation between mortality and level of economic development, Population Studies, 29, 231-48.

Pritchett, L. and Summers, L. (1996) Wealthier is healthier, Journal of Human Resources, 31, 841-68.

Rosen, S. and Taubman, P. (1982) Some socioeconomic determinants of mortality, in Economics of Health Care (Eds) J. van der Gagg, W. B. Neeman and T. Tsukahara, Praeger Publishers, New York, pp. 255-71.

Self, S. and Grabowski, R. (2003) How effective is public health expenditure in improving overall health? A cross-country analysis, Applied Economics, 35, 835-45.

Thornton, J. (2002) Estimating a health production function for the US: some new evidence, Applied Economics, 34, 59-62.

Tandon, A., Murray, C. J. L., Lauer, J. A. and Evans, D. (2000) Measuring overall health system performance for 191 countries, GPE discussion Paper Series 30, World Health Organization.

World Health Report (2000) Health systems: improving performance, World Health Organization, Geneva, Switzerland.

World Development Indicators (2002) World Bank, Washington D.C.

Zaim, O., Färe, R. and Grosskopf, S. (2001) An economic approach to achievement and improvement indexes, Social Indicators Research, 56, 91-118.

Zurayak, H., Sholkamy, H., Younis, N. and Khattab, H. (1997) Women's health problems in the Arab World: a holistic policy perspective, International Journal of Gynaecology and Obstetrics, 58, 13-21. 